\title{
The Effect of Tonsillectomy and Adenoidectomy on Right Ventricle Function and Pulmonary Artery Pressure by Using Doppler Echocardiography in Children
}

\author{
Onur Çağlar Acar ${ }^{1}$ Abdurrahman Üner ${ }^{1} \cdot$ Mehmet Fatih Garça ${ }^{2} \cdot$ Ibrahim Ece ${ }^{1} \cdot$ Serdar Epçaçan $^{1} \cdot$ Mahfuz Turan $^{2}$ \\ Ferhat Kalkan ${ }^{3}$ \\ ${ }^{I}$ Division of Pediatric Cardiology, Department of Pediatrics, ${ }^{2}$ Department of Otorhinolaryngology, Yüzüncü Yll University Medical Faculty, Van; \\ ${ }^{3}$ Department of Otolaryngology, Training and Research Hospital, Van, Turkey
}

Objectives. The purpose of the present study is to emphasize the efficacy of the myocardial performance index and tricuspid annular plane systolic excursion (TAPSE) in the determination of impaired cardiac functions and recovery period following the treatment in children with adenoid and/or tonsillar hypertrophy.

Methods. Fifty-three healthy children after routine laboratory, imaging and clinical examinations, with adenoid and/or tonsillar hypertrophy were evaluated before and 3 months after adenotonsillectomy for cardiac functions using M mode and Doppler echocardiography.

Results. The mean age of cases was $6.4 \pm 3.0$ years, 34 (65\%) were male, and 19 (35\%) were female. Pulmonary hypertension was observed to be mild in 3 patients and moderate in 1 patient preoperatively. When the preoperative and postoperative echocardiographic measurements of the patients were compared, the tricuspid valve E wave velocity, the E/ A ratio (E, early diastolic flow rate; A, late diastolic flow rate), and the TAPSE values were determined to be significantly higher postoperatively $(P<0.05)$. The tricuspid valve deceleration time, the isovolumetric relaxation time and the systolic pulmonary artery pressure were found to be significantly lower compared to the preoperative values $(P<0.05)$.

Conclusion. Adenoidectomy and/or tonsillectomy may prevent cardiac dysfunctions that can develop in the later periods due to adenoid and/or tonsil hypertrophy in children, before the appearance of the clinical findings of cardiac failure.

Keywords. Adenotonsillectomy; Right Ventricular Failure; Myocardial Performance Index; Tricuspid Annular Plane Systolic Excursion

\section{INTRODUCTION}

Stenosis developing in the upper respiratory tract due to various causes may further lead to obstructive sleep apnea, increased

- Received January 23, 2015

Revised May 16, 2015

Accepted July 8, 2015

- Corresponding author: Mehmet Fatih Garça

Department of Otorhinolaryngology, Yüzüncü Yll University Medical

Faculty, 65100,Van,Turkey

Tel: +90-432-215-0473, Fax: +90-432-216-7519

E-mail: fatihgarca@hotmail.com pulmonary artery pressure and right ventricular failure. The most common causes of upper respiratory tract stenosis in childhood are adenoid hypertrophy on the posterior wall of the nasopharynx and tonsillar palatine hypertrophy on the lateral walls of the oropharynx [1]. Echocardiography, as a noninvasive and reproducible diagnostic method, is quite useful in evaluating the ventricular functions in these patients [1-5]. This study has aimed to evaluate the efficacy of tricuspid annular plane systolic excursion (TAPSE) and myocardial performance index (MPI) in demonstrating the changes in the preoperative and postoperative cardiac functions in children for whom an operation for ad-

Copyright (C) 2016 by Korean Society of Otorhinolaryngology-Head and Neck Surgery.

This is an open-access article distributed under the terms of the Creative Commons Attribution Non-Commercial License (http://creativecommons.org/licenses/by-nc/4.0)

which permits unrestricted non-commercial use, distribution, and reproduction in any medium, provided the original work is properly cited. 
enoid and/or tonsillar palatine hypertrophy has been planned, and who have been assessed as being healthy on routine examination.

\section{MATERIALS AND METHODS}

The approval was obtained from the Van Yüzüncü Yıl University, Faculty of Medicine, Clinical Practice Ethics Committee. Fiftythree children aged between 2 and 13, who were scheduled for adenoidectomy, tonsillectomy, or adenotonsillectomy due to various causes in the Department of Otorhinolaryngology were evaluated. Adenoid tissue, tonsillar palatines, or both were hypertrophic in these patients. The cases were diagnosed as adenoid hypertrophy using the flexible nasal endoscopy and stenosis in the air column on examination and lateral nasopharyngeal radiography. Tonsillar palatines hypertrophy was diagnosed by oropharyngeal examination [6]. All the patients were preoperatively tested for blood count, biochemical blood analyses, chest $\mathrm{X}$-ray and echocardiography. The echocardiographies were evaluated preoperatively and 3 months after the operation by a cardiologist.

\section{Echocardiographic examination}

The same investigator performed the echocardiography with a General Electric Vivid Pro 7 (Vingmed Ultrasound, Horten, Norway) using 3- to 6-MHz probes preoperatively and 3 months after the operation. The American Echocardiography Association guideline was taken into consideration during the evaluation. The cardiac functions of all the patients were evaluated using 2 dimensioned, M-mode and Doppler echocardiography. Echocardiography was performed in a silent room, with the patient lying on the left, side calm and breathing comfortably. Measurements were performed through the parasternal window; long axis and short axis, apical window; 4- and 5-chamber views. The left ventricular ejection fraction was calculated using the Teicholtz formula. Through the apical 4-chamber views, the time interval between the end and beginning of mitral flow (a1), early diastolic flow rate $(\mathrm{E})$, late diastolic flow rate (A), E/A ratio, and the deceleration time (DT) were obtained using pulse wave Doppler echocardiography and locating the sample volume at the end-

Table 1. Demographic characteristics of the study group

\begin{tabular}{lc}
\hline Characteristic & Value \\
\hline Age $(\mathrm{yr})$ & $6.4 \pm 3.0$ \\
Sex & $34(64)$ \\
$\quad$ Male & $19(36)$ \\
Female & $23.13 \pm 11.92$ \\
Weight $(\mathrm{kg})$ & $116.17 \pm 19.23$ \\
\hline
\end{tabular}

Values are presented as mean \pm SD or number (\%). points of the mitral valves. The sampling volume was obtained by apical 5 -chamber image, and the left ventricular ejection time (b1) and isovolumetric relaxation time (IVRT) were obtained by locating in the left ventricular outflow tract. In the right ventricle measurements through apical 4-chamber image, locating the sample volume at the endpoints of the tricuspid valves and the right ventricle outflow tract in the parasternal axis, the time interval between the end and beginning of tricuspid flow (a2), the right ventricular ejection time (b2), E and A flow rates, E/A ratio, DT, and IVRT were obtained. In the measurement of the MPI, the formulae of (a1-b1)/b1 for the left ventricle, and (a2-b2)/b2 for the right ventricle were used [7]. The TAPSE value was measured in millimeter $(\mathrm{mm})$ during right ventricular systole in the right ventricle and tricuspid valve intersection point through the apical 4-chamber images of M mode echocardiography. Systolic pulmonary artery pressure was calculated through the jet of tricuspid valve insufficiency.

\section{Statistical analysis}

The SPSS ver. 15 (SPSS Inc., Chicago, IL, USA) was used to assess the results of the study for statistical analyses. The variables were given as mean $\pm \mathrm{SD}$. The Student $t$-test was used for the descriptive statistics and the paired samples. For all the results, a $P$ value of $<0.05$ was accepted as significant.

\section{RESULTS}

The demographic characteristics of patients have been shown in Table 1 . All the patients were clinically healthy and their chest $\mathrm{X}$-rays and electrocardiographies were normal. Their laboratory findings (blood count, biochemistry values, and coagulation tests) were within normal limits. However, preoperatively, 3 patients had mild and 1 patient had moderate pulmonary hypertension. The preoperative and the 3rd month postoperative echocardiography results for the left and the right ventricles have been presented in Tables 2, 3. Accordingly, in the compari-

Table 2. Left ventricular echocardiography findings

\begin{tabular}{lccc}
\hline Variable & Preoperative & Postoperative & $P$-value \\
\hline LVEF $(\%)$ & $74.5 \pm 3.59$ & $76.1 \pm 3.44$ & 0.716 \\
FS $(\%)$ & $35.7 \pm 3.14$ & $37.8 \pm 3.01$ & 0.659 \\
E $(\mathrm{cm} / \mathrm{sec})$ & $88.5 \pm 11.0$ & $85 \pm 20.7$ & 0.476 \\
A (cm/sec) & $71.6 \pm 11.1$ & $73.7 \pm 15.7$ & 0.599 \\
E/A ratio & $1.28 \pm 0.20$ & $1.14 \pm 0.33$ & 0.077 \\
DT (msec) & $195 \pm 22.0$ & $193 \pm 15.7$ & 0.759 \\
IVRT (msec) & $80.7 \pm 12.3$ & $79.6 \pm 8.1$ & 0.726 \\
MPI & $0.37 \pm 0.07$ & $0.35 \pm 0.07$ & 0.182 \\
\hline
\end{tabular}

Values are presented as mean \pm SD.

LVEF, left ventricle ejection fraction; FS, fraction of shortening; E, early diastolic flow rate; A, late diastolic flow rate; DT, deceleration time; IVRT, isovolumetric relaxation time; MPI, myocardial performance index. 
Table 3. Right ventricular echocardiography findings

\begin{tabular}{lccc}
\hline Variable & Preoperative & Postoperative & $P$-value \\
\hline E $(\mathrm{cm} / \mathrm{sec})$ & $62.9 \pm 15.1$ & $74.1 \pm 17.7$ & 0.041 \\
$\mathrm{~A}(\mathrm{~cm} / \mathrm{sec})$ & $58.1 \pm 14.0$ & $61.0 \pm 15.6$ & 0.718 \\
E/A & $1.08 \pm 0.30$ & $1.21 \pm 0.32$ & 0.038 \\
DT $(\mathrm{msec})$ & $212 \pm 18.1$ & $196 \pm 13.5$ & 0.001 \\
IVRT $(\mathrm{msec})$ & $96.8 \pm 9.69$ & $77.8 \pm 5.53$ & 0.001 \\
PAB $(\mathrm{mmHg})$ & $30.2 \pm 5.02$ & $26.4 \pm 2.17$ & 0.003 \\
TAPSE $(\mathrm{mm})$ & $15.9 \pm 1.78$ & $20.7 \pm 3.07$ & 0.001 \\
MPI & $0.39 \pm 0.07$ & $0.32 \pm 0.06$ & 0.002 \\
\hline
\end{tabular}

Values are presented as mean $\pm \mathrm{SD}$.

$\mathrm{E}$, early diastolic flow rate; $\mathrm{A}$, late diastolic flow rate; $\mathrm{DT}$, deceleration time; IVRT, isovolumetric relaxation time; PAB, pulmonary artery pressure; TAPSE, tricuspid annular plane systolic excursion; MPI, myocardial performance index.

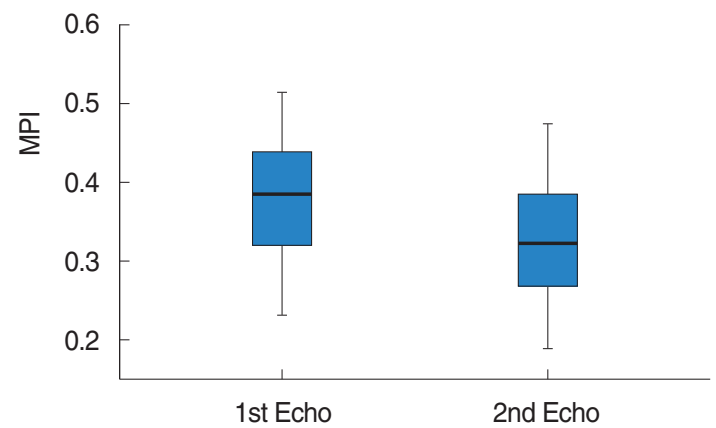

Fig. 1. Pre- and postoperative changes in myocardial performance index (MPI) of tricuspid valve. Echo, echocardiography.

son of the preoperative and postoperative $\mathrm{E}, \mathrm{A}$, the $\mathrm{E} / \mathrm{A}$ ratio for the mitral valve, DT, IVRT, MPI, the tricuspid valve A values, and the left ventricular ejection fraction and the shortening fraction values at the pre- and postoperative periods were found to be nonsignificant. E, E/A, and the TAPSE levels for the tricuspid valve were significantly higher postoperatively $(P<0.05)$. Furthermore, the DT, IVRT, and MPI values and the systolic pulmonary artery pressures were found to be significantly lower after the operation compared to the preoperative values. The tricuspid valve MPI and TAPSE changes before and after the operation have been demonstrated in Figs. 1, 2.

\section{DISCUSSION}

The most common cause of upper respiratory tract obstruction and sleep apnea in children is adenotonsillar hypertrophy [1]. Due to upper respiratory tract occlusion in these children, chronic oral respiration and consequent malocclusion and abnormal maxillofacial development may develop. Furthermore, snoring, sleeping with the mouth open, enuresis, bad academic performance and sleep disorders secondary to oxygenation disorders have been observed [1-6]. Chronic hypoventilation secondary to adenotonsillar hypertrophy may result in impaired

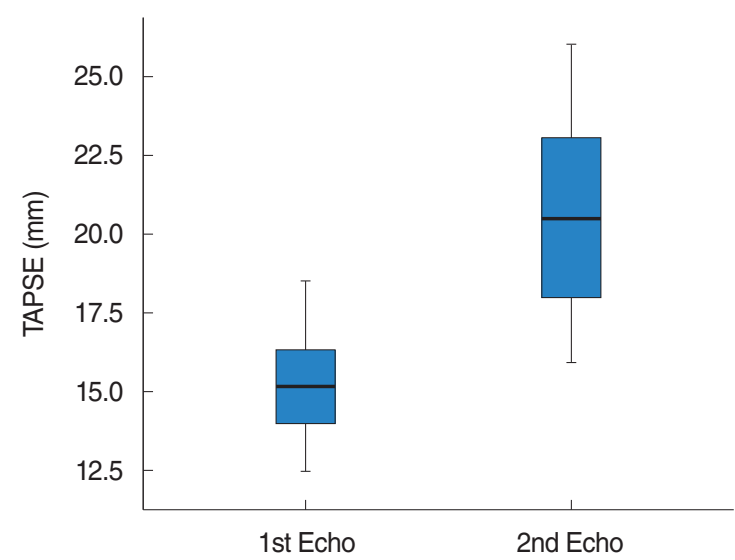

Fig. 2. Pre- and postoperative changes in tricuspid annular plane systolic excursion (TAPSE) of tricuspid valve. Echo, echocardiography.

functions [7-9]. As a result of alveolar hypoventilation due to upper airway obstruction, pulmonary vasoconstriction, increased pulmonary artery pressure and increased right ventriular afterload may ensue $[9,10]$. Pulmonary edema, right ventricular hypertrophy and right ventricular insufficiency may occur $[6,8]$. Hypoxemia, hypercapnia, pulmonary hypertension and right ventricular hypertrophy findings consequent to adenotonsillar hypertrophy rapidly recover following management of the obstruction $[4,11]$. Removing the upper airway obstruction by adenoidectomy alleviates the chronic alveolar hypoxia and results in regressed pulmonary vasoconstriction and decreased pulmonary vascular resistance [8]. In the study of Duman et al. [12], the authors found the pulmonary hypertension rate due to adenotonsillar hypertrophy as 3.3\%. In the study of Abd ElMoneim et al. [3], adenoidectomy decreased the mean pulmonary artery pressure by $4 \mathrm{mmHg}$. Moreover, Martha et al. [8] reported in their study that a significant decrease was observed in pulmonary artery pressure 3 or 4 months following adenoidectomy. In the present study, 4 patients $(7.5 \%)$ had preoperative pulmonary hypertension. Three months after adenotonsillectomy, a significant decrease in the pulmonary artery pressure was observed, which is consistent with the literature (Table 3 ) $(P<0.05)$. Furthermore, the pulmonary artery pressure levels decreased to normal in four patients with high levels.

Diastolic function disorders in the right and left ventricles are seen before systolic dysfunction. The mechanism of diastolic dysfunction may be intra- or extramyocardial. As a result of chronic right ventricular pressure, compensatory hypertrophy may develop against decreased wall tension. This may impair the right ventricular diastolic functions. IVRT is the first parameter that is disrupted in right ventricular dysfunction $[13,14]$. In the study of Gan et al. [14], as a marker of diastolic dysfunction in chronic right ventricular pressure elevation, the authors reported prolonged IVRT, decreased $\mathrm{E}$ flow rate, increased A flow rate, and decreased E/A ratio. Stojnic et al. [13] also demon- 
strated prolongation in IVRT in pulmonary hypertension. In the study performed by Shedeed [7], patients with asthma had significantly higher IVRT than that of the control group. In type 1 diastolic dysfunction, IVRT and DT were prolonged, the E flow rate was decreased, the A flow rate was increased, and the E/A ratio was decreased [14]. In this study, the preoperative results were consistent with type I diastolic dysfunction. Following surgery, significant decreases in the right ventricular IVRT and DT (Table 3) $(P<0.05)$, significant increases in the $\mathrm{E}$ flow rate and E/A $(P<0.05)$ were observed.

TAPSE, which is easy and fast to perform by Doppler echocardiography, provides direct information about the right ventricular systolic functions. A TAPSE value above $20 \mathrm{~mm}$ is accepted as normal. In the study performed on cases with severe interstitial lung diseases by Nowak et al. [15], it was found that the TAPSE value was significantly lower compared to that of the control group. Forfia et al. [16] measured the TAPSE value to be less than $18 \mathrm{~mm}$ in cases with severe right ventricular dysfunction and pulmonary hypertension. In recent years, many studies related with TAPSE have been performed in diseases like cardiac failure, hypertension, and thyrotoxicosis [17-20]. In our study, the preoperative TAPSE value was lower than normal as a marker of disrupted right ventricular functions in patients. Three months after adenotonsillectomy, the TAPSE value elevated to normal limits and were significantly different from the preoperative values $(P<0.05)$.

Echocardiography has vital importance in evaluating the ventricular functions in children. However, evaluation of the right ventricular functions by echocardiography is difficult because of the complex structural geometry of the right ventricle and changes in the contraction pattern. Therefore, MPI, which is easily applied by Doppler echocardiography, being noninvasive, reproducible and unaffected by the heart rate, is clinically more beneficial in the evaluation of the global functions of the right ventricle. MPI is a combination of systolic and diastolic time intervals. It is also used to evaluate the left ventricular functions. It is defined as the sum of the index isovolumetric contraction time and the IVRT divided by the ejection time [21,22]. In the study of Grignola et al. [23] that was performed on 6 merino sheep, the authors created a pulmonary hypertension model and they demonstrated that the right ventricle MPI significantly increased in pulmonary hypertension. As a result, they reported that MPI is a sensitive marker for right ventricular dysfunction in acute pulmonary hypertension. In the present study, the right ventricular MPI significantly decreased after the operation (Table 3) $(P<0.05)$. The MPI values showed that both the systolic and the diastolic functions of the right ventricle were destroyed before surgery and returned to normal after surgery, consistent with type I diastolic dysfunction and the TAPSE values detected by Doppler echocardiography. No significant difference was observed between the preoperative and the postoperative left ventricular systolic and diastolic functions (Table 2$)(P>0.05)$.
In conclusion, adenotonsillectomy may prevent cardiac dysfunctions that can develop in the later periods due to adenoid and/or tonsillar hypertrophy in children. Furthermore, before the appearance of the clinical findings of cardiac failure in these patients, conventional and Doppler echocardiography may reveal the impairment in the right ventricular systolic and diastolic functions. Recovery of cardiac function after surgery may be followed by repeated measurements.

\section{CONFLICT OF INTEREST}

No potential conflict of interest relevant to this article was reported.

\section{ACKNOWLEDGMENTS}

We would like to thank the families of patients in our hospital for their willingness to allow their children' participation in this investigation. Special thanks to Sıdık Keskin, MD, for statistical support.

\section{REFERENCES}

1. Ramakrishna S, Ingle VS, Patel S, Bhat P, Dada JE, Shah FA, et al. Reversible cardio-pulmonary changes due to adeno-tonsilar hypertrophy. Int J Pediatr Otorhinolaryngol. 2000 Oct;55(3):203-6.

2. Gorur K, Doven O, Unal M, Akkus N, Ozcan C. Preoperative and postoperative cardiac and clinical findings of patients with adenotonsillar hypertrophy. Int J Pediatr Otorhinolaryngol. 2001 May;59 (1):41-6.

3. Abd El-Moneim ES, Badawy BS, Atya M. The effect of adenoidectomy on right ventricular performance in children. Int J Pediatr Otorhinolaryngol. 2009 Nov;73(11):1584-8.

4. Yilmaz MD, Onrat E, Altuntas A, Kaya D, Kahveci OK, Ozel O, et al. The effects of tonsillectomy and adenoidectomy on pulmonary arterial pressure in children. Am J Otolaryngol. 2005 Jan-Feb;26(1): 18-21.

5. Kay DJ, Mehta V, Goldsmith AJ. Perioperative adenotonsillectomy management in children: current practices. Laryngoscope. 2003 Apr; 113(4):592-7.

6. Brodsky L, Moore L, Stanievich JF. A comparison of tonsillar size and oropharyngeal dimensions in children with obstructive adenotonsillar hypertrophy. Int J Pediatr Otorhinolaryngol. 1987 Aug;13 (2):149-56.

7. Shedeed SA. Right ventricular function in children with bronchial asthma: a tissue Doppler echocardiographic study. Pediatr Cardiol. 2010 Oct;31(7):1008-15.

8. Martha VF, Moreira Jda S, Martha AS, Velho FJ, Eick RG, Goncalves SC. Reversal of pulmonary hypertension in children after adenoidectomy or adenotonsillectomy. Int J Pediatr Otorhinolaryngol. 2013 Feb;77(2):237-40.

9. Sie KC, Perkins JA, ClarkeWR. Acute right heart failure due to adenotonsillar hypertrophy. Int J Pediatr Otorhinolaryngol. 1997 Jul; 41(1):53-8. 
10. Koc S, Aytekin M, Kalay N, Ozcetin M, BurucuT, Ozbek K, et al.The effect of adenotonsillectomy on right ventricle function and pulmonary artery pressure in children with adenotonsillar hypertrophy. Int J Pediatr Otorhinolaryngol. 2012 Jan;76(1):45-8.

11. Tezer MS, Karanfil A, Aktas D. Association between adenoidal-nasopharyngeal ratio and right ventricular diastolic functions in children with adenoid hypertrophy causing upper airway obstruction. Int J Pediatr Otorhinolaryngol. 2005 Sep;69(9):1169-73.

12. Duman D, Naiboglu B, Esen HS, Toros SZ, Demirtunc R. Impaired right ventricular function in adenotonsillar hypertrophy. Int J Cardiovasc Imaging. 2008 Mar;24(3):261-7.

13. Stojnic BB, Brecker SJ, Xiao HB, Helmy SM, Mbaissouroum M, Gibson DG. Left ventricular filling characteristics in pulmonary hypertension: a new mode of ventricular interaction. Br Heart J. 1992 Jul;68(1):16-20.

14. Gan CT, Holverda S, Marcus JT, Paulus WJ, Marques KM, Bronzwaer JG, et al. Right ventricular diastolic dysfunction and the acute effects of sildenafil in pulmonary hypertension patients. Chest. 2007 Jul;132(1):11-7.

15. Nowak J, Jastrzebski D, Streb W, Rozentryt P, Wojarski J, Greif M, et al. Right ventricular function in patients with severe interstitial lung disease: a Tissue Doppler imaging study. J Physiol Pharmacol. 2008 Dec;59 Suppl 6:531-8.

16. Forfia PR, Fisher MR, Mathai SC, Housten-Harris T, Hemnes AR, Borlaug BA, et al. Tricuspid annular displacement predicts survival in pulmonary hypertension. Am J Respir Crit Care Med. 2006 Nov; 174(9):1034-41.

17. Miller D, Farah MG, Liner A, Fox K, Schluchter M, Hoit BD. The re- lation between quantitative right ventricular ejection fraction and indices of tricuspid annular motion and myocardial performance. J Am Soc Echocardiogr. 2004 May;17(5):443-7.

18. Kjaergaard J, Iversen KK, Akkan D, Moller JE, Kober LV,Torp-Pedersen C, et al. Predictors of right ventricular function as measured by tricuspid annular plane systolic excursion in heart failure. Cardiovasc Ultrasound. 2009 Nov;7:51.

19. Karaye KM, Habib AG, Mohammed S, Rabiu M, Shehu MN. Assessment of right ventricular systolic function using tricuspid annularplane systolic excursion in Nigerians with systemic hypertension. Cardiovasc JAfr. 2010 Jul-Aug;21(4):186-90.

20. Hong JY, Park DG, Yoo JJ, Lee SM, Kim MK, Kim SE, et al. The correlation between left ventricular failure and right ventricular systolic dysfunction occurring in thyrotoxicosis. Korean Circ J. 2010 Jun; 40(6):266-71.

21. Tei C, Ling LH, Hodge DO, Bailey KR, Oh JK, Rodeheffer RJ, et al. New index of combined systolic and diastolic myocardial performance: a simple and reproducible measure of cardiac function. A study in normals and dilated cardiomyopathy. J Cardiol. 1995 Dec; 26(6):357-66.

22. Vonk MC, Sander MH, van den Hoogen FH, van Riel PL, Verheugt FW, van Dijk AP. Right ventricle Tei-index: a tool to increase the accuracy of non-invasive detection of pulmonary arterial hypertension in connective tissue diseases. Eur J Echocardiogr. 2007 Oct;8(5): 317-21.

23. Grignola JC, Gines F, Guzzo D. Comparison of the Tei index with invasive measurements of right ventricular function. Int J Cardiol. 2006 Oct;113(1):25-33. 